\title{
Effectiveness of pain relief in labour: survey of 1000 mothers
}

\author{
BARBARA MORGAN，C J BULPITT，P CLIFTON，P J LEWIS
}

\begin{abstract}
The amount of pain that had been experienced by 1000 women during vaginal delivery of a live child was determined by interview within 48 hours of delivery. Patients had been offered a choice of analgesia, and 536 had received epidural analgesia: pain relief was greatest in this group, just over half having had a painless labour. The duration of pain was also reduced by a third in this group even though patients who had received an epidural block had tended to have longer labour and an incidence of assisted delivery of $51 \%$ compared with $6 \%$ in the remainder. Seventy-two per cent of the patients receiving an epidural had had as much pain as they had expected. A similar proportion (70\%) was reported with simpler analgesic methods, suggesting that women may expect a certain amount of pain in labour and request further analgesic treatment when this is exceeded.
\end{abstract}

\section{Introduction}

In 1967 Beazley et al ${ }^{1}$ published a classic study of the efficacy of different forms of analgesia in labour. Since then epidural analgesia has been widely introduced for pain relief in labour even for routine practice. Few systematic attempts have been made, however, to compare its efficacy with that of more traditional methods of pain relief. We report here the relative effectiveness of different methods of obstetric analgesia in a consecutive series of 1000 women.

\section{Patients and method}

One thousand women were interviewed after vaginal delivery of a live child; this was a consecutive series over four months at Queen

Department of Anaesthetics, Institute of Obstetrics and Gynaecology, Queen Charlotte's Maternity Hospital, London

BARBARA MORGAN, MB, FFARCs, senior lecturer

Department of Medical Statistics and Epidemiology, London School of Hygiene and Tropical Medicine

C J BULPITT, MD, FRCP, senior lecturer

P CLIFTON, SRN, HV, research assistant

Department of Clinical Pharmacology, Royal Postgraduate Medical School, Hammersmith Hospital, London

P J LEWIS, MD, FRCP, senior lecture
Charlotte's Hospital, London. The survey did not influence routine clinical practice in the hospital. Methods of pain relief in labour had been discussed with patients at antenatal class by midwives and anaesthetists. Patients were encouraged to choose the method of analgesia that they wished to receive. Epidural analgesia was available for all mothers requesting it unless there was a medical contraindication.

Patients requesting an epidural block were not initially given any other analgesia. Some patients received pethidine first and an epidural block later because of inadequate pain relief. Patients who received epidural blocks and Entonox (premixed nitrous oxide and oxygen $50 / 50 \mathrm{v} / \mathrm{v}$, self-administered) either had blocks that were inadequate for part of the time or found Entonox to be unsatisfactory when used alone. Patients given pethidine received $150 \mathrm{mg}$ pethidine and promethazine $25 \mathrm{mg}$ intramuscularly with a further dose of $100 \mathrm{mg}$ pethidine if required. Pudendal block was performed when either pain was inhibiting delivery or outlet forceps delivery was to be performed.

Each mother was interviewed within 48 hours after delivery by a research midwife who had not met her before. The interviewer, always the same trained midwife, examined the patient's records and noted the analgesia received, parity, the method of induction (if any), whether oxytocin acceleration had been used, the method of delivery, the duration of labour, and the race, religion, and social class of the patient. Social class was assigned by husband's occupation into professional and managerial (I and II), clerical and skilled manual (III), and semi-skilled and unskilled (IV and V).

The efficacy of the analgesia was assessed by questioning patients as follows: (1) Did you feel pain in labour and delivery despite treatment? (Yes or No). (2) How much pain did you experience? (Patients were presented with a $10 \mathrm{~cm}$ linear analogue ${ }^{2}$ scale graded between 0 (no pain at all) and $100 \mathrm{~mm}$ (as much pain as is possible to imagine); they marked the scale to indicate their estimate of pain.) (3) Do you feel that this was the correct amount of pain in labour ? (Less/Correct/More/Don't know.) (4) How long did the pain last? (Minutes.)

\section{Results}

The mean $( \pm S D)$ age of the mothers was $28 \pm 4 \cdot 8$ years. Social classes I and II accounted for 230 of the 1000 patients. Table I shows the other principle characteristics of the patients and their labours. Patients received one of nine categories of analgesia: 80 did not receive any analgesia, 128 received Entonox, 24 did not require any analgesia but required a pudendal block for delivery, 120 received pethidine, 88 received pethidine and Entonox, 423 received epidural analgesia alone, 38 received epidural analgesia plus Entonox, and 47 received pethidine and epidural analgesia; 52 received miscellaneous combinations. Twenty-eight of this last group received epidural blocks that were either ineffective or were given after other ineffective analgesia; the remainder received various intramuscular and intravenous opiates and regional blocks.

TABLE I-Parity, induction, mode of delivery, pain, and duration of labour in the 1000 patients

\begin{tabular}{|c|c|c|c|c|c|c|c|}
\hline $\begin{array}{c}\text { Analgesia } \\
\text { received }\end{array}$ & $\begin{array}{c}\text { No of } \\
\text { patients }\end{array}$ & $\begin{array}{l}\text { No }(\%) \text { of } \\
\text { primiparas }\end{array}$ & $\begin{array}{l}\text { No }(\%) \\
\text { induced }\end{array}$ & $\begin{array}{l}\text { No (\%) of } \\
\text { assisted } \\
\text { deliveries }\end{array}$ & $\begin{array}{c}\text { No (\%) with } \\
\text { painless } \\
\text { labour }\end{array}$ & $\begin{array}{l}\text { No }(\%) \text { with } \\
\text { more pain } \\
\text { than expected }\end{array}$ & $\begin{array}{c}\text { Mean } \pm S D \\
\text { duration of } \\
\text { labour } \\
\text { (hours) }\end{array}$ \\
\hline $\begin{array}{l}\text { None } \\
\text { Entonox } \\
\text { Pethidine } \\
\text { Pethidine + Entonox } \\
\text { Pudendal block } \\
\text { Epidural } \\
\text { Epidural + Entonox } \\
\text { Pethidine + epidural } \\
\text { Miscellaneous }\end{array}$ & $\begin{array}{r}80 \\
128 \\
120 \\
88 \\
24 \\
423 \\
38 \\
47 \\
52\end{array}$ & $\begin{array}{r}9(11) \\
32(25) \\
60(50) \\
38(43) \\
6(25) \\
275(65) \\
18(47) \\
32(68) \\
34(65)\end{array}$ & $\begin{array}{r}9(11) \\
21(16) \\
22(18) \\
16(18) \\
4(17) \\
148(35) \\
12(32) \\
12(25) \\
21(40)\end{array}$ & $\begin{array}{r}1(1) \\
8(6) \\
9(7) \\
5(6) \\
4(17) \\
217(51) \\
15(39) \\
25(33) \\
41(78)\end{array}$ & $\begin{array}{c}6(7) \\
15(12) \\
15(12) \\
16(18) \\
2(6) \\
251(59) \\
13(33) \\
29(62) \\
7(13)\end{array}$ & $\begin{array}{r}24(31) \\
34(27) \\
36(30) \\
30(34) \\
6(27) \\
114(27) \\
10(27) \\
15(33) \\
26(50)\end{array}$ & $\begin{array}{r}5 \cdot 2 \pm 3 \cdot 5 \\
6 \cdot 7 \pm 3 \cdot 0 \\
7 \cdot 3 \pm 3 \cdot 2 \\
7 \cdot 6 \pm 4 \cdot 1 \\
5 \cdot 6 \pm 4 \cdot 2 \\
10 \cdot 5 \pm 4 \cdot 6 \\
8 \cdot 6 \pm 4 \cdot 7 \\
13 \cdot 1 \pm 6 \cdot 1 \\
10 \cdot 7 \pm 4 \cdot 9\end{array}$ \\
\hline & 1000 & $504(50)$ & 265 & 325 (33) & 354 (35) & $295(30)$ & $8 \cdot 8$ \\
\hline
\end{tabular}


TABLE II-Mean ( $\pm S D$ ) pain scores and mean duration of pain in labour in the nine analgesic groups

\begin{tabular}{|c|c|c|c|c|c|c|c|c|c|}
\hline & $\begin{array}{c}\text { No } \\
\text { analgesia }\end{array}$ & Entonox & Pethidine & $\begin{array}{l}\text { Pethidine } \\
\text { plus } \\
\text { Entonox }\end{array}$ & $\begin{array}{c}\text { Pudendal } \\
\text { block }\end{array}$ & Epidural & $\begin{array}{l}\text { Epidural } \\
\text { plus } \\
\text { Entonox }\end{array}$ & $\begin{array}{l}\text { Pethidine } \\
\text { plus } \\
\text { epidural }\end{array}$ & Miscellaneous \\
\hline $\begin{array}{l}\text { Pain score } \\
\text { Duration of pain (min) }\end{array}$ & $\begin{array}{c}70 \pm 2 \cdot 6 \\
50\end{array}$ & $61 \pm 3 \cdot 1$ & $58 \pm 3 \cdot 1$ & $57 \pm 3 \cdot 4$ & $68 \underset{73}{61} 1 \cdot 9$ & $29 \pm 3 \cdot 7$ & $51 \pm 4 \cdot 2$ & $30 \pm 3 \cdot 8$ & $69 \pm 3 \cdot 3$ \\
\hline
\end{tabular}

Table I also gives the proportions of primiparas in the groups. There were significantly more primiparas in the groups that received an epidural $(64 \% v 33 \% ; \mathrm{p}<0.001)$. Conversely, primiparas were underrepresented in the groups who received either no analgesia or Entonox alone.

Patients whose labour was induced were more likely to receive an epidural analgesic $(71 \% v 48 \% ; \mathrm{p}<0.001)$. Patients who had an epidural block had a significantly longer labour than those who did not (mean 10.5 hours $v 6.4$ hours; $\mathrm{p}<0.001$ ). The proportion requiring assisted delivery was much greater in patients who received epidural analgesia compared with those who did not $(51 \% v 6 \% ; \mathrm{p}<0.001)$. There were no significant differences in age, social class, race, or religion between women receiving different types of analgesia.

Table II shows the pain scores in labour reported by the patients together with the mean duration of pain. Patients who received epidural alone had the lowest average pain score $(29 \mathrm{~mm} v 61 \mathrm{~mm})$ and the highest proportion of women who said that they had not experienced any pain. Consistent with this, the duration of pain was shortest among patients who received epidural analgesia alone, epidural analgesia plus Entonox, and pethidine plus epidural analgesia. About one-third of all mothers experienced more pain than they had expected. This proportion was remarkably similar in all analgesic groups (mean $29 \%$ ) with the exception of the miscellaneous group, in which the proportion was $50 \%$.

\section{Discussion}

This evaluation of a routine obstetric analgesic service had as its principal aim the assessment of efficacy. Such an assessment necessitates a reliable and reproducible technique for the measurement of pain. ${ }^{3}$ Unfortunately, pain is subjective and measurement difficult. The visual linear analogue method proved to be easily understood by the patients and also provided a score of perceived pain.

Because of the technical complexity of epidural analgesia the provision of an on-demand service for all patients in labour is extremely costly. Such facilities were provided but, interestingly, only 536 patients chose the option promising a painless labour. This is curious, particularly as the midwives had encouraged mothers to have epidural analgesia in labour as they considered it to be safe and more efficacious than other methods. They adhered firmly to the dictum that "an epidural block without demur is the right of every mother in labour."4 A partial explanation may be that in many patients labour is relatively painless until the cervix is almost fully dilated, when insufficient time is left for epidural blockade to take effect.

Of the 120 mothers who chose pethidine alone, $15(12 \%)$ had a completely pain-free labour. Similarly, 15 (12\%) of the 128 mothers who received Entonox alone had complete pain relief. This contrasts with 251 (59\%) of those who had an epidural alone. Sixteen $(18 \%)$ of the 88 mothers who received both pethidine and Entonox reported a pain-free labour, which is a much higher proportion than that reported by Holdcroft and Morgan. ${ }^{5}$ In their survey no patients were pain free after pethidine alone, $3.8 \%$ were pain free after Entonox alone, and $1.1 \%$ were pain free after pethidine plus Entonox. Some of the difference may be explained by the fact that the patients in the present survey selected their own analgesia.

The incidence of assisted delivery in patients receiving epidurals was high at $51 \%$. The epidural group included a higher proportion of primiparas and women with induced labours and longer labours. It cannot be assumed, however, that epidural analgesia prolongs labour ${ }^{6-8}$ and increases the likelihood of forceps delivery. Other evidence suggests that this is the case, but longer labours and induced labours may possibly be more painful and hence the mothers are more likely to opt for epidural analgesia.

It is interesting to compare our results with those of Beazley et $a l,{ }^{1}$ who in a clinical trial in 1967 achieved painless labour in $23 \%$ of patients, using opiates or paracervical and pudendal blocks, and an almost pain-free labour in a further $37 \%$. Our expectation of much better results with modern treatment was not fulfilled as only $35 \%$ of the mothers in the present survey had a pain-free labour. The 150 patients of Beazley et al were selected for their expectation of spontaneous delivery, and $87 \%$ had normal deliveries. Only $67 \%$ of the mothers in the present survey, however, had a spontaneous singleton delivery.

One of the advantages of hospital delivery given by Beazley et al was adequate pain relief within half an hour of complaint. ${ }^{1}$ Despite considerably more expenditure on pain relief in labour in the past 15 years our results remain similar. Possibly, however, the expectations of anaesthetists are too high. During labour it is largely the mother who controls the amount of pain she experiences by requesting further analgesia. This may explain why all the analgesic methods, apart from epidural blocks, produced the same pain scores, the patients regulating their own analgesia. The present results indicate that $71 \%$ of the mothers had only as much pain as they expected even though the pain scores seem quite high. The fact that $46 \%$ of mothers chose not to take up the promise of a painless labour with an epidural block is also consistent with this idea. Maternal attitudes to pain in labour and its relation to a satisfactory experience of childbirth are obviously important, and we shall report on this later.

A realistic expectation to encourage in antenatal patients is that modern methods can relieve, although not totally abolish, pain in labour. The promise of a totally painless labour is probably unrealistic and may even be unwanted.

\section{References}

${ }^{1}$ Beazley JM, Leaver EP, Morewood JHM, Bircumshaw J. Relief of pain in labour. Lancet 1967; i:1033-5.

${ }^{2}$ Huskisson EC. Measurement of pain. Lancet 1974 ;i:1127-31.

${ }^{3}$ Revill SI, Robinson JO, Rosen M, Hogg MIJ. The reliability of a linear analogue for evaluating pain. Anaesthesia 1976;31:1191-8.

4 Steel GC. Epidural nerve block. In: Chamberlain G, ed. Contemporary obstetrics and gynaecology. London: Northwood Publications, 1977: 178-83.

${ }^{5}$ Holdcroft A, Morgan M. The assessment of the analgesic effect in labour of pethidine and 50 per cent nitrous oxide in oxygen (Entonox). Fournal of Obstetrics and Gynaecology of the British Commonwealth 1974;81:603-7.

6 Hoult IJ, MacLennan AH, Carrie LES. Lumbar epidural analgesia in labour: relation to fetal malposition and instrumental delivery. $\mathrm{Br} \mathrm{Med} \mathcal{F}$ $1977 ; \mathrm{i}: 14-6$.

? Willack-Lund G, Lindmark G, Nilsson BA. Effect of segmental epidural block on the condition of the infant during the neonatal period. Acta Anaesthesiol Scand 1979;23:301-11.

${ }^{8}$ Studd JWW, Selwyn Crawford J, Duignan NM, Rowbotham CJF, Hughes AO. The effect of lumbar epidural analgesia on the outcome of labour of spontaneous onset. Br $\mathcal{F}$ Obstet Gynaecol 1980;87:1015-21.

(Accepted 9 fuly 1982) 